\title{
Selected allergic diseases of the gastrointestinal tract
}

\author{
Andrzej Kuźmiński ${ }^{1}$, Michał Przybyszewski ${ }^{1}$, Małgorzata Graczyk ${ }^{1}$, Magdalena Żbikowska-Gotz ${ }^{1}$, \\ Natalia Sokołowska-Ukleja ${ }^{1}$, Alina Tomaszewska², Zbigniew Bartuzi ${ }^{1}$ \\ ${ }^{1}$ Department of Allergology, Clinical Immunology and Internal Diseases, Nicolaus Copernicus University in Torun, \\ Ludwik Rydygier Collegium Medicum in Bydgoszcz, Poland \\ ${ }^{2}$ Dermatology Clinical Ward, $10^{\text {th }}$ Military Research Hospital and Polyclinic, Bydgoszcz, Poland
}

Gastroenterology Rev 2020; 15 (3): 194-199

DOI: https://doi.org/10.5114/pg.2019.87681

Key words: food allergy, gastrointestinal tract.

Address for correspondence: Andrzej Kuźmiński MD, Department of Allergology, Clinical Immunology and Internal Diseases, Nicolaus Copernicus University, Ludwik Rydygier Collegim Medicum, 75 Ujejskiego St, 85-168 Bydgoszcz, Poland, phone: +48 501006 104, e-mail: jendrek75@interia.pl

\begin{abstract}
Clinical symptoms of food allergy may affect not only the digestive tract, but also the respiratory system, skin, or cardiovascular system. They may manifest themselves as gastrointestinal problems, asthma attacks, hives, or anaphylactic shock. Allergic reactions of the gastrointestinal tract may be IgE-independent (oral anaphylaxis syndrome, acute gastrointestinal reactions), mixed (eosinophilic gastrointestinal disorders), or IgE-independent (food-induced enterocolitis, proctitis, or enteropathy). The most serious conditions in which allergic background plays or can play an important role are: oral anaphylaxis syndrome, aphthous stomatitis, reflux disease, acute and chronic allergic reactions of gastric mucosa, irritable bowel syndrome, and eosinophilic gastrointestinal disorders.
\end{abstract}

\section{Introduction}

The symptomatology of food allergy is extremely rich, and symptoms can affect every system and organ. As well as the most characteristic symptoms of the gastrointestinal tract, symptoms may include the respiratory system, the skin, and the cardiovascular system.

Clinical forms of gastrointestinal allergies can take different forms. The most important ones in which an allergic background plays or can play an important role are: oral anaphylaxis syndrome (OAS), aphthous stomatitis (RAS), reflux disease, acute and chronic allergic reactions of gastric mucosa, irritable bowel syndrome (IBS), and eosinophilic gastrointestinal disorders (EGID).

\section{Oral allergy syndrome}

Oral allergy syndrome is a set of symptoms localised in the oral cavity and appearing in patients with pollinosis after ingestion of specific fruits and vegetables. Symptoms occur immediately after allergenic food comes into contact with the oral mucosa and include swelling, itching, redness, and/or burning of the oral mucosa and throat. The syndrome may be isolated or associated with systemic symptoms (2-10\%), and $1.7 \%$ of patients may develop anaphylactic shock. It is estimated that about $8 \%$ of children and $5 \%$ of adults with inhaled allergy are affected by OAS [1].

OAS occurs most often in people who are primarily allergic to the main birch allergen (Bet v1) and develops after eating some fruits such as apples, cherries, pears, or the following vegetables: celery, carrots, hazelnuts, soya, or peanuts. The main allergens of these foods show a high degree of homology of the amino acid sequence (> 70\%) with the main birch allergen, and therefore IgE antibodies specific to Bet $v 1$ recognise them, initiating the development of an allergic reaction [1, 2].

In the diagnosis of OAS, accurate history and diagnostic tests (skin prick tests (SPT), specific IgE, double-blind placebo-controlled assay (DBPCFC), and allergenic component assay) are of paramount importance. It is considered that the occurrence of OAS symptoms after the consumption of cooked and processed plant foods may arouse suspicion of systemic reactions [1, 2].

OAS treatment includes the avoidance and heat treatment of food inducers and the use of symptomatic drugs. Data on the effectiveness of specific immunotherapies are inconclusive [2]. 
It is believed that people with OAS exposed to anaphylactic shock require adrenaline and glucocorticosteroids (GCS). This group includes patients with documented systemic reaction history, with hypersensitivity to peanuts, nuts, and mustard, and with adverse reactions to cooked plant products regardless of the severity of the reaction, and with exposure to specific foods occurring in a defined area where the risk of severe reaction to the product is higher (e.g. peach in Mediterranean countries) [3].

\section{Recurrent aphthous stomatitis (RAS)}

Returning aphtha is a disease of the mucous membrane of the oral cavity, consisting of the periodical occurrence of erosions covered with fibre surrounded by inflammatory mucosa. Aphtha is a common disease; it is estimated that it may affect $11-30 \%$ of the Polish population [4].

The cause of the aphthae remains unknown. It is believed that their formation may be caused by genetic factors, stress, trauma, bacteria, viruses, hormonal disorders, deficiency of Fe, Zn, Se, B, and $\mathrm{B}_{12}$ vitamins, folic acid, as well as digestive tract diseases such as celiac disease, Crohn's disease, ulcerous colitis, Behcet's disease, and food allergies (mainly to milk, nuts, tomatoes, citrus, and coffee) [5].

Allergies are considered to be an important cause of the development of aphthae. In 1986 Wright et al. demonstrated that among 11 patients with severe RAS, as many as six responded with an improvement in dietary treatment [6]. In a 1991 Swedish study (Nolan) of 27 patients with RAS, food allergy was found in as many as 12 of them [7]. A 2007 Turkish study (Gonul) of 27 patients with RAS showed that food allergy may be responsible for 35-50\% of aphthae cases, and improvement after elimination diet was demonstrated in $25-75 \%$ of patients [8]. In a Chinese study published in 2017, 128 patients with severe RAS showed 17 (13.3\%) food allergy patients in 128 patients, and the most common allergens were milk, egg, seafood, wheat flour, fish, and soya. The paper also describes a case of a man with severe RAS in the course of allergies to cow's milk proteins, in whom after the implementation of dietary treatment, ulceration healed and no recurrence was observed within 6 months of observation [9].

Diagnostics of allergic aphthae included a detailed interview, clinical examination, assessment of the allergic background, and exclusion of other causes of aftershave formation. When assessing the allergic background of RAS, SPT, patch tests, slgE, diagnostics of allergenic components, and DBPCFC are performed, while the choice of food to be tested is based on the results of other tests. If DBPCFC cannot be performed, 1-2-week elimination di- ets based on an interview, SPT, and slgE are used. Lack of improvement with high probability excludes food allergy as a cause of RAS [10].

The aim of aphthae treatment is to reduce pain, shorten the time of illness, return to normal functioning, and reduce the frequency and severity of recurrences. Elimination diets are used both in the diagnosis and treatment of RAS caused by food allergy. The principle is to eliminate foods causing or even suspected of causing RAS, and the success of these diets depends on the correct identification of allergens, the ability of the patient to maintain a diet, and the assumption that other factors do not cause aphthae at the same time. Pharmacological treatment includes topical use of steroids in the form of mouthwash or mouthwash and amlexanox - an immunomodulating agent with anti-inflammatory and anti-allergic effects, which when used in the form of a $5 \%$ paste reduces pain, shortens the time of illness, and prevents relapse. In the case of resistant lesions, systemic GCS and immunomodulators such as levamisole, thalidomide, colchicine, dapsone, and pentoxifylline are used [11].

\section{Reflux disease (GERD) due to allergic causes}

Reflux disease is the discharge of gastric contents into the oesophagus causing troublesome symptoms and/or specific complications. GERD is believed to occur in $3-10 \%$ of the population.

There are two types of GERD: primary GERD, associated with anatomical and functional disorders of the lower oesophageal sphincter; and secondary GERD, associated with systemic diseases, including food allergy [12].

In the aetiopathogenesis of allergic GERD two main relationships are taken into account:

- The influence of food allergy on GERD: the relationship between GERD and food allergy is particularly visible in the child population (below 3 years of age) and is estimated at about $40 \%$. The main allergen responsible for GERD is cow's milk protein. In 2004 Nielsen performed DBPCFC to demonstrate that in children with severe GERD allergy to cow's milk occurs with a frequency of 56\% [13]. In 2016, Yukselen and Celtik demonstrated that among GERD patients resistant to treatment, food allergy occurred with a frequency of $43 \%$ (including $38.4 \%$ of allergy to cow's milk only) [14].

- The influence of GERD treatment on the development of food allergy: in 2003 Untersmayr et al. demonstrated that an increase in the $\mathrm{pH}$ of gastric juice may disturb protein digestion, lead to neo-antigen formation, stimulate slgE synthesis, and lead to the development of food allergy [15]. Trikha et al. in 2013 showed that 
children using PPI for 1 year because of GERD had a two-times higher incidence of food allergies compared to both untreated and conservatively treated children [16].

An evaluation of the coexistence of GERD and food allergy is problematic. Because GERD and allergy to cow's milk proteins may have similar symptoms, it is not always possible to determine that allergy is a cause of reflux on the basis of an interview. Additionally, cases of primary reflux coexisting with food allergy are described in the literature [17]. Historically, when analys ing the records of 24-hour $\mathrm{pH}$ monitoring, it was believed that the character of these records was different in primary GERD than in allergy-induced reflux. In the first case irregular drops of intraoesophageal $\mathrm{pH}$ below 4 were described, while in the second case a rapid increase of $\mathrm{pH}$ after a meal and its slow decrease afterwards were described [17]. However, it is now believed that allergy to milk increases the incidence of shortterm episodes of weak acid reflux [18].

The results of conservative reflux treatment in children have been analysed in numerous reports. In many cases of failure of anti-reflux treatment, it turned out that the patient was diagnosed with a food allergy and the introduction of an elimination diet resulted in the resolution of symptoms [17]. In the case of primary reflux, anti-reflux treatment led to a decrease in eosinophilic infiltration of the oesophagus, which was not observed in secondary reflux due to cow's milk allergy [19].

Considering that allergy to cow's milk proteins is a common cause of GERD in children, it is necessary to determine whether the reflux is primary or secondary. In the first case, the basis for treatment is anti-reflux treatment, while in the second case, treatment should be started with an elimination diet, which leads to the decrease and gradual elimination of not only allergy symptoms, but also GERD [20].

\section{Allergic reactions from the stomach}

Allergic reactions from the stomach affect mainly the paediatric population. It is estimated that they can occur in about $1 \%$ of children.

Allergic reactions from the stomach can occur in the form of acute or chronic inflammatory conditions.

The acute allergic reaction of the gastric mucosa is usually caused by allergens of cow's milk and chicken eggs. A few minutes after allergenic food is administered, the stomach's motor activity is intensified, and strong, contractile abdominal pains and vomiting appear. Then swelling and congestion of the mucous membrane develops, bloody petechiae appear, and consequently inflammation develops, which affects the antral part of the stomach in particular. In some cases, the inflammation is so intense that it can cause the symptoms of pseudostenosis of the pylorus.

In the case of chronic allergic reactions of the stomach and duodenum there is no typical syndrome of symptoms characteristic of an allergic background. The ailments are usually dyspeptic with a feeling of fullness, flatulence, abdominal pain, loss of appetite, and abnormal bowel movements.

The 2-4-week elimination test, food provocation tests, DBPCFC, and endoscopic allergen provocation test (TEPA) are important in the diagnosis.

The treatment includes elimination diets, and in more severe cases also protein hydrolysates and elementary diets [21].

\section{Irritable bowel syndrome (IBS)}

Many studies suggest that some IBS patients may be affected by undiagnosed food allergy or food intolerance. This relationship is estimated at up to $5-50 \%$ of all IBS cases. A number of studies were carried out to estimate the correlation between food allergy and IBS. Addolorato in 2000 showed that up to $25 \%$ of patients with food allergy or intolerance may have IBS [22]. In 2004, Atkinson et al. concluded that elimination diets may be helpful in reducing the symptoms of IBS [23]. In 2006, Monsbakken et al. demonstrated that $70 \%$ of IBS subjects had food-related symptoms, and that $62 \%$ of patients reduced or excluded certain products from their diet for this reason [24]. In 2006, Alpers estimated that the relationship between IBS symptoms and the occurrence of food allergy and intolerance is multifactorial and dietary treatment may have a significant impact on the reduction of the ailment [25]. Camilleri in 2006 showed that $20-65 \%$ of patients attributed IBS symptoms to food allergen hypersensitivity. He concluded that elevated levels of slgE and IgG4 may be responsible for hypersensitivity reactions in a subgroup of IBS patients, and also found significantly elevated levels of slgE for wheat, beef, pork, lamb, soya, and chicken egg white [26]. In 2006, Galliani performed skin and slgE tests in 55 patients with IBS, showing the occurrence of food hypersensitivity in $16 \%$ of them [27]. In recent years, there have been two interesting studies evaluating the relationship between food allergy and IBS. In the 2014 Jones et al. study of 30,000 patients with gastrointestinal disorders, $44.8 \%$ of patients with IBS had allergic diseases, while among patients with other functional disorders $32.7 \%$ had allergic diseases [28]. In 2015, Pearson et al. analysed 512 IBS patients and the proportion with a food allergy to be $43.5 \%$. The study also included a case report of a 27-year-old woman with severe, long-term IBS and bronchial asthma, in whom, after 
therapy with omalizumab for asthma was initiated, abdominal ailments gradually subsided. During the 4-year anti-IgE therapy no recurrence of IBS symptoms was observed, which may suggest an allergic background as a cause of symptoms [29].

The mechanism of increased incidence of IBS in patients with food allergy is not well known. An increased permeability of the intestinal mucosa is suggested, which results in an increased number of mast cells [30]. It was shown that administration of the fattening cell stabiliser ketotifen reduces visceral sensation in IBS patients compared to placebo. The results with sodium cromoglycate are inconclusive [30].

The initial treatment of food allergy-related IBS includes an elimination diet, although it has not been established which products should be eliminated and for how long. In addition, there is discussion on whether the treatment should be empirical or based on allergic tests. Ketotifen and disodium cromoglycate are recommended as drugs that stabilise mast cells and reduce visceral sensation. The role of the GCS is unclear. They are believed to reduce symptoms; however, not all cases have been correlated with the reduction of eosinophilic infiltration [31].

\section{Eosinophilic gastrointestinal disorders (EGID)}

Acidophilic gastroenteritis is a rare disease in patients of all ages with a peak in the third decade of life. It occurs in patients regardless of race and place of residence, slightly more frequently in males than in females $(1.4: 1.0)$. The incidence of the disease is estimated at 1-10 per 100,000 patients [32].

EG aetiology is not well known. The association with allergy suggests the co-occurrence of allergic diseases, current atopy features in $50-75 \%$ of patients, peripheral eosinophilia in $50-70 \%$ of cases, increased concentration of total IgE, reduction of symptoms after elimination diet, and elimination of symptoms as a result of steroid therapy in $90 \%$. For other reasons, drugs (enalapril, gemfibrozil, carbamazepine, $\alpha$-interferon) or viral infections are mentioned, e.g. in CMV, EBV, and HSV children, but the genetic condition of EG has not been proven [33].

The characteristic features common to all forms of EG include the presence of gastrointestinal symptoms, eosinophilic infiltrations in the gastrointestinal tract, peripheral eosinophilia, lack of other causes of eosinophilic infiltrations, and lack of pathological involvement of other organs [34].

This group of diseases includes eosinophilic oesophagitis, eosinophilic gastroenteritis, eosinophilic colitis, and eosinophilic colitis.

\section{Eosinophilic oesophagitis (EO)}

Eosinophilic oesophagitis is regarded as a specific form of food allergy. In the last 30 years, a rapid increase by more than 10 -fold in the prevalence of EO has been observed, the cause of which is unknown [35].

The complaints reported by patients with EO are non-specific. In small children feeding difficulties, inhibition of body weight gain, and growth dominate; in older children and adults dysphagia and episodes of food entrapment dominate. The diagnosis is based on histological examination with $\geq 15$ eosinophils at $400 x$ magnification on a surface of $\sim 0.3 \mathrm{~mm}^{2}$.

EO is treated with elimination diets and pharmacotherapy (IPP, montelukast, and GCS with local effects). Attempts have also been made to use IL-5 anti-inflammatory antibodies, while in the study phase antieotaxin-1, CCR-3 blocker, $\alpha 4 \beta 7$ integrin blockers, IgE antiinflammatory antibodies, and IL-10 agonists are still used. After 6-12 weeks of treatment, the efficacy of controlled endoscopy with histological examination of cuttings is evaluated [35].

\section{Eosinophilic gastroenteritis}

Eosinophilic gastroenteritis is an extremely rare disease affecting both adults and children. The frequency of its occurrence is estimated at about $1: 100,000$ patients. The disease occurs in three forms: mucosal, muscular (30\%), and serum $(10 \%)[34,36]$.

In about $80 \%$ of patients, eosinophilia in peripheral blood and in some cases elevated clgE concentration is observed. Allergic tests are usually useless in determining the allergen causing EG, and the ascites fluid is characterised by a high content of eosinophils during serum involvement [34]. The number of eosinophilic infiltrates in the stomach or intestinal wall exceeding 20-25 is required for diagnosis [34, 36].

Pharmacological treatment includes the use of GCS. Cromones are less commonly used drugs with unproven efficacy. In the case of steroid dependence and frequent relapses, attempts are made to treat with azathioprine, 6-mercaptopurine, mycophenolate mofetil, and PPI. Similarly to EO, dietary treatment includes elimination diets and elementary diets, and surgical treatment is recommended for complications such as intussusception or intestinal perforation [34].

\section{Eosinophilic colitis (EC)}

Eosinophilic colitis is rarely diagnosed. It occurs with equal frequency in both sexes, both among infants and less frequently among young adults. Illnesses in the elderly are extremely rare [37].

Abnormal immune response to food allergens is suspected to be caused by T lymphocyte-dependent EC. In 
infants EC is most often induced by an allergic reaction dependent on cow's milk or soya protein, although EC has also been described in exclusively breastfed children [34].

EC laboratory tests may be accompanied by an increased number of eosinophils in the blood and the presence of eosinophils in the stool. slgE for food allergens is detected in $50 \%$ of cases. Histologically, eosinophilic infiltrates can be found in the plaque and mucous membrane crypts [38]. Because the number of eosinophils in the normal large intestine may vary from 35 in the caecum to five in the rectum, it is important to determine in detail where the slice was taken from [39]

Treatment of EC depends on the age of the patient. Usually, in children it is sufficient to exclude the causal allergen factor (usually cow's milk protein or soya beans) from the diet, which results in elimination of clinical symptoms within $72 \mathrm{~h}$ [38]. In adults we use GKS and 5-ASA acid preparations. In cases of relapse and/or steroid dependence, it is advisable to consider azathioprine or 6-mercaptopurine therapy as well as the use of montelukast. There is no evidence of efficacy of other drugs, such as ketotifen or sodium cromoglycate $[34,38]$.

\section{Conflict of interest}

The authors declare no conflict of interest.

\section{References}

1. Mrówka-Kata K, Fira R, Namysłowski G, et al. Zespół Amlot-Lessofa - zespół alergii jamy ustnej. Forum Med Rodz 2007; 1: 355-7.

2. Bohle B, Zwolfer B, Heratizadeh A, et al. Cooking birch pollen-related food: divergent consequences for IgE and T cell mediated reactivity in vitro and in vivo. J. Allergy Clin Immunol 2006; 118: 242-8.

3. Panaszek B. Zespół alergii jamy ustnej. Alergia 2012; 2: 6-13.

4. Nowak M, Górska R. Współczesne poglądy na etiopatogenezę aft nawracających (RAS). Nowa Stomatol 2011; 1: 35-8.

5. Śleboda Z, Szponar E, Kowalska A. Recurrent aphthous stomatitis: genetic aspects of etiology. Adv Dermatol Allergol 2013 30: 96-102.

6. Wright A, Pryan F, Willingham S, et al. Food allergy or intolerance in severe recurrent aphthous ulceration of the mouth. BMJ 1986; 292: 1237-8.

7. Nolan A, Lamey PJ, Miligan KA, et al. Recurrent aphthous ulceration and food sensitivity. J Oral Pathol Med 1991; 20: 473-5.

8. Gonul M, Gul U, Cakmak S, et al. The role of the diet in patients with recurrent aphthous stomatitis. Eur J Dermatol 2007; 17 97-8.

9. Wang X, Li X, Shi H. Analysis of recurrent oral ulcer in patients with or without food allergy. Biom Res 2017; 28: 3490-4.

10. Barrons R. Treatment strategies for recurrent oral aphthous ulcers. Am J Health Syst Pharm 2001; 58: 41-50.

11. Scully C, Gorsky M, Lozada-Nur F. The diagnosis and management of recurrent aphthous stomatitis: a concencus approach. J Am Dent Assoc 2003; 134: 200-7.
12. Semeniuk J, Kaczmarski M. Gastroesophageal reflux (GER) in children and adolescents with regard to food intolerance. Adv Med Sci 2006; 51: 321-6.

13. Nielsen R, Bindslev-Jensen C, Kruse-Andersen S, et al. Severe gastroesophageal reflux disease and cow milk hypersensitivity in infants and children: disease association and evaluation of a new challenge procedure. J Pediatr Gastroenterol Nutr 2004; 39: 383-91.

14. Yukselen A, Celtik C. Food allergy in children with refractory gastroesophageal reflux disease. Pediatr Int 2016; 58: 254-8.

15. Untersmayr E, Schöll I, Swoboda I, et al. Antacid medication inhibits digestion of dietary proteins and causes food allergy: a fish allergy model in BALB/c mice. J Allergy Clin Immunol 2003; 112: 616-23.

16. Trikha A, Baillargeon J, Kuo Y, et al. Development of food allergies in patients with gastroesophageal reflux disease treated with gastric acid suppressive medications. Pediatr Allergy Immunol 2013; 24: 582-8.

17. Kamer B, Chilarski A, Lange A, et al. Gastroesophageal reflux in infants with food allergy. Med Sci Monit 2000; 6: 348-52.

18. Borrelli O, Mancini M, Thapar N, et al. Cow's milk challenge increases weakly acidic reflux in children with cow's milk allergy and gastroesophageal reflux disease. J Pediatr 2012; 161: 476-81.

19. Walsh S, Antonioli D, Goldman H, et al. Allergic esophagitis in children: a clinicopathological entity. Am J Surg Pathol 1999; 23: 390-6.

20. Mowszet K, Iwańczak B, Matusiewicz K, et al. Refluks żołądkowo-przełykowy w alergii pokarmowej u dzieci. Nowa Pediatria 2000; 4: 22-3.

21. Romański B, Bartuzi Z. Alergia i nietolerancja pokarmów. Wydawnictwo Ślask, Katowice 2004; 505-614.

22. Addolorato G, Capristo E, Ghittoni G, et al. Risk factor for irritable bowel syndrome: role of food allergies. Am J Gastroenterol 2000; 95: 2130-1.

23. Atkinson $\mathrm{W}$, Sheldon $\mathrm{T}$, Shaath $\mathrm{N}$, et al. Food elimination based on IgG antibodies in irritable bowel syndrome: a randomised controlled trial. Gut 2004; 53: 145964.

24. Monsbakken K, Vandvik P, Farup P. Perceived food intolerance in subjects with irritable bowel syndrome - etiology, prevalence and consequences. Eur J Clin Nutr 2006; 60: 667-72.

25. Alpers D. Diet and irritable bowel syndrome. Curr Opin Gastroenterol 2006; 22: 136-9.

26. Camilleri $M$. Is there a role of food allergy in irritable bowel syndrome and functional dyspepsia? A systematic review. Neurogastroenterol Motil 2006; 18: 595-601.

27. Galliani E. Prevalence of food intolerance and/or food hypersensitivity in irritable bowel syndrom patients. Gastroenterology Suppl 2006; 2. A1-747.

28. Jones $M$, Walker $M$, Ford $A$, et al. The overlap of atopy and functional gastrointestinal disorders among 23471 patients in primary care. Aliment Pharmacol Ther 2014; 40: 382-91.

29. Pearson J, Niven R, Meng J, et al. Immunoglobulin E in irritable bowel syndrome: another target for treatment? A case report and literature review. Therap Adv Gastroenterol 2015; 8: 270-7.

30. Lee H, Park J, Park D, et al. Mucosal mast cell count is associated with intestinal permeability in patients with diarrhea 
predominant irritable bowel syndrome. J Neurogastroenterol Motil 2013; 19: 244-50.

31. Castellano M, Cimbollek S, Quiralte J. Defining the role of food allergy in a population of adult patients with eosinophilic esophagitis. Inflamm Allergy Drug Targets 2010; 9: 257-62.

32. Pineton de Chambrun G, Gonzalez F, Canva JY, et al. Natura history of eosinophilic gastroenteritis. Clin Gastroenterol Hepatol 2011; 9: 950-6.

33. Roy-Ghanta S, Larosa D, Katzka D. Atopic characteristics of adult patients with eosinophilic esophagitis. Clin Gastroenterol Hepatol 2008; 6: 531-5.

34. Rogowska A. Eozynofilowe choroby przewodu pokarmowego. Gastroenterol Klin 2012; 4: 105-16.

35. Hruz P, Straumann A, Bussmann C, et al. Escalating incidence of eosiophilic esophagitis: a 20-year prospective, population-based study in Olten County, Switzerland. J Allergy Clin Immunol 2011; 128: 1349-50.

36. Iwańczak B, Iwańczak F. Eozynofilowe choroby zapalne przewodu pokarmowego. Pediatr Współcz Gastroenterol Hapatol Żyw Dzieci 2010; 3: 91-6.

37. Yan BM, Shaffer EA. Primary eosinophilic disorders of the gastrointestinal tract. Gut 2009; 58: 721-32.

38. Rothenberg ME. Eosinophilic gastrointestinal disorders (EGID). J Allergy Clin Immunol 2004; 113: 11-28.

39. Okapara N, Aswad B, Baffy G. Eosinophilic colitis. World J Gastroenterol 2009; 15: 2975-79.

Received: 11.07.2019

Accepted: 30.07.2019 